\title{
GONÇALVES BRAGA: O JOVEM MESTRE PORTUGUÊS DE MACHADO DE ASSIS
}

\section{CRISTIANE NASCIMENTO RODRIGUES}

Universidade Federal de São Carlos

São Carlos, São Paulo, Brasil

Resumo: Este artigo trata da presença do jovem poeta português, Francisco Gonçalves Braga, no início da carreira literária de Machado de Assis. Nesse sentido, serão lidos e discutidos os seguintes poemas machadianos: "Saudades" e "No álbum do Sr. F. G. Braga", publicados na Marmota Fluminense e dedicados a Gonçalves Braga.

Palavras-chave: Romantismo; Francisco Gonçalves Braga; Machado de Assis; poesia; Marmota Fluminense.

\section{GONÇALVES BRAGA: THE YOUNG PORTUGUESE MASTER OF MACHADO DE ASSIS}

Abstract: This article seeks to discuss the presence of the young Portuguese poet, Francisco Gonçalves Braga, in Machado de Assis' early career. In order to do this, two poems written by Machado de Assis ("Saudades" and "No álbum do Sr.F.G.Braga") both published by Marmota Fluminense and dedicated to Gonçalves Braga will be analyzed.

Keywords: Romanticism; Francisco Gonçalves Braga; Machado de Assis; poetry; Marmota Fluminense. 


\section{Braga: primeiro mestre}

A

utor de um livro só, o poeta português Francisco Gonçalves Braga (1836-1860) teve participação ativa no período inicial da formação poética de Machado de Assis. De acordo com Galante de Sousa (1979, p. 19), Gonçalves Braga chegou a Pernambuco aos onze anos de idade, ${ }^{1}$ ou seja, em 1847, e se transferiu para a cidade do Rio de Janeiro em $1854 .^{2}$ Segundo Jean-Michel Massa (2009, p. 105-113), ao chegar à capital do império, Braga se tornou caixeiro-viajante e, ao mesmo tempo, estabeleceu relações com o meio literário. Colaborou, entre outros, no Periódico dos Pobres (1850-1856 e 1870-1879) e na Marmota Fluminense (1849-1864). Por fim, ainda participou da Petalógica, associação literária formada por um grupo de intelectuais que se reunia nos fundos da livraria do editor Paula Brito. ${ }^{3}$

Gonçalves Braga foi relativamente importante para o círculo fluminense de jovens escritores, pois existem várias referências a ele nos periódicos da época, seja como poeta, seja como tradutor de peças francesas e italianas. ${ }^{4}$ Além disso, Braga publicou o seu único livro de poemas em 1856, as Tentativas poéticas. Ele também publicou oito poemas no Álbum do Grêmio Literário Português no Rio de Janeiro (1858), ${ }^{5}$ que reúne textos de, entre outros, A. J. de Carvalho Lima, Ernesto Cibrão, Fernando Castiço, J. A. Santos Cartiço, J. Belmiro da Silva, J. Coelho Lousada e de Faustino Xavier de Novais, que, mais tarde, viria a ser cunhado de Machado de Assis.

Quando da morte de Braga em 10 de março de 1860, o Grêmio Literário, de cuja comissão de redação ele participou (DIÁRIO DO RIO DE JANEIRO, 1858, p. 1), fez celebrar uma missa (CORREIO MERCANTIL..., 1860a, p. 3). Dias depois, foi publicada uma crônica em sua homenagem no

\footnotetext{
${ }^{1}$ No Diário de Pernambuco (1847, p. 2), é possível ler o nome de Francisco Gonçalves Braga entre os passageiros de um navio saído do Porto.

${ }^{2}$ Em O Liberal Pernambucano (1854, p. 4), consta o nome de Braga entre os que saíram de navio em direção ao Rio de Janeiro no dia 25 de abril de 1854.

${ }^{3}$ Francisco de Paula Brito (1809-1861) foi um jornalista, poeta, dramaturgo, tradutor e editor brasileiro. Em 1831, ele já tinha tipografia própria e seu jornal de maior prestígio foi a Marmota Fluminense, em que colaboraram escritores como Joaquim Manuel de Macedo, Teixeira e Sousa, Machado de Assis e Juvenal Galeno. Paula Brito trabalhava em benefício do progresso das letras no Brasil oitocentista, permitindo que muitos poetas jovens publicassem textos em sua revista (MASSA, 2009, p. 83-90).

4 Há um documento na Biblioteca Nacional (Coleção Conservatório Dramático Brasileiro) que comprova que Braga também tentava escrever dramas. Trata-se de um requerimento a Diogo Soares da Silva de Bivar, solicitando exame censório para a peça de sua composição: "Maria Espanhola" (BRAGA, 1854).

5 São eles: "Beranger", "Desejos", "Garrett", "Os cinco sentidos", "Transição", "Pedido", "A uma menina" e "A Lamartine" (CARVALHO LIMA et al., 1858).
} 
Correio Mercantil, e Instrutivo, Político, Universal (1848-1868). Segundo o texto,

Tinha vinte e cinco anos o pobre poeta que morreu há pouco; confiava no futuro e estudava com afinco, na solidão, a que se condenara, antevendo a coroa de louro, alvo de seus esforços. Publicou há quatro anos um volume de poesias, - frutos colhidos antes de sazão; mas nos quais o espírito do crítico já podia reconhecer a fertilidade do terreno que os produzia: eram as suas tentativas poéticas; ele próprio assim as crismara. Alguns amigos, que sabiam o que ele podia criar com aquela rica imaginação, com a força de vontade que tinha, apontaram-lhe os defeitos do seu livro; desde então recolheu-se ao silêncio; apenas de longe em longe os seus amigos aplaudiam entre si uma poesia de Francisco Gonçalves Braga; era um suspiro, um hino que o peito do poeta já não podia conter e que transbordava [...]. (CORREIO MERCANTIL..., 1860b, p. 1)

O único livro de Gonçalves Braga, Tentativas poéticas, contém poemas compostos em Pernambuco e no Rio de Janeiro. Os sessenta poemas tratam do papel do poeta; o exílio e a saudade do país natal; a solidão; a miséria humana por desfrutar de pouco dinheiro; a morte; o amor e a religião. Além disso, existem muitos poemas escritos em homenagem a outros escritores, políticos e à cantora lírica Arsène Charton Demeur, para quem, inclusive, Machado de Assis veio a compor um poema em 1856 (ASSIS, 1856, p. 4). Nas epígrafes ou nas dedicatórias dos poemas das Tentativas poéticas figuram nomes de portugueses como Alexandre Herculano, Almeida Garrett, Augusto Emílio Zaluar, Lopes de Mendonça, António Feliciano de Castilho, João d’Aboim, Luís Vaz de Camões, Bernardim Ribeiro, Bocage, Filinto Elísio, Camilo Castelo Branco e João de Lemos; de italianos como Torquato Tasso e Dante Alighieri e dos brasileiros Gonçalves de Magalhães, Antônio Gonçalves Teixeira e Sousa e do próprio Machado de Assis.

Gonçalves Braga também frequentou o Grupo dos Cinco (MASSA, 2009, p. 151-153), formado pelo advogado dr. Caetano Filgueiras, por José Joaquim Cândido de Macedo Jr. - o Macedinho -, Casimiro de Abreu e Machado de Assis, que se reunia no escritório de Filgueiras para discutir e ler poesia. ${ }^{6}$ Ao justificar a exclusão de alguns textos de Crisálidas (1864) na "Advertência" das Poesias completas (1901), Machado de Assis, referindo-se

${ }^{6}$ Os encontros aconteceram a partir de 1857, ou seja, após o regresso de Casimiro de Abreu de Portugal (MASSA, 2009, p. 151-153). 
ao Grupo dos Cinco, observou que "Todos se foram para a morte, ainda na flor da idade, e, exceto o nome de Casimiro de Abreu, nenhum se salvou" (ASSIS, 1901, p. 5).

Segundo Magalhães Júnior (2008, p. 41), Braga foi o amigo que teve grande presença na iniciação literária de Machado de Assis, tanto que este "dedicou repetidos tributos públicos de afeto e de admiração" ao poeta português. O primeiro poema publicado pelo brasileiro na Marmota Fluminense, "Ela", contém epígrafe de Braga, ${ }^{7}$ assim como o segundo, "A palmeira" (ASSIS, 1855a, p. 3), que também foi a ele dedicado; "Saudades" (ASSIS, 1855e, p. 4) foi escrito em sua homenagem; "A saudade" (ASSIS, $1855 \mathrm{~b}, \mathrm{p} .3$ ) contém epígrafe de Braga de um poema de mesmo nome, e, por fim, há ainda o poema "No álbum do Sr. F. G. Braga" (ASSIS, 1855d, p. 3-4) em que o jovem Machado comparou o companheiro aos consagrados poetas portugueses: Bernardim Ribeiro, Bocage, Almeida Garrett e Camões, obtendo um poema em resposta, "Ao Senhor J. M. M. d'Assis" (BRAGA, 1855, p. 1).

Sobre a relação entre Machado e Braga, Wilton Marques comentou:

Conheceram-se ao longo do segundo semestre de 1854, pouco depois da chegada do português ao Rio de Janeiro. A partir de setembro de 1854, Braga começou a mandar versos para o Periódico dos Pobres e foi possivelmente por seu intermédio que Machado de Assis conseguiu publicar nesse mesmo período seu primeiro poema (Soneto à Ilma. Sra. D. P. J. A.), uma vez que não parece ser o caso de mera coincidência histórica que, logo abaixo do soneto machadiano, viesse impresso o poema "O mendigo" de Braga. Poucos meses depois, a partir de novembro de 1854, o poeta português passou a colaborar na Marmota Fluminense, o que, inclusive, levanta a possibilidade de Machado de Assis ter sido apresentado a Francisco de Paula Brito também por intermédio de Braga. (MARQUES, 2016, p. 19)

Em suma, o predomínio do nome do português nos primeiros poemas machadianos só confirma o fato de que Braga se tornou referência para a composição poética do brasileiro. Nesse sentido, veja-se, a seguir, a leitura e análise dos poemas "Saudades" e "No álbum do Sr. F. G. Braga", dedicados ao poeta português, e publicados em 1855, no periódico Marmota Fluminense.

7 Os versos da epígrafe são: "Nunca vi, - não sei se existe / Uma deidade tão bela, / Que tenha uns olhos brilhantes / Como são os olhos d'ela!" (ASSIS, 1855c, p. 3). 


\section{Machado e o tributo a Braga}

O primeiro poema de Machado de Assis em homenagem a Gonçalves Braga leva como título "Saudades", foi escrito em 25 de fevereiro de 1855 e publicado na Marmota Fluminense no dia $1^{0}$ de maio do mesmo ano. Nessa mesma edição da revista está presente um poema de Braga, intitulado "Saudação poética ao Senhor Conselheiro António Feliciano de Castilho", por ocasião da chegada ao Brasil do autor do Tratado de versificação portuguesa (1851). Esse poema de Braga possui epígrafe com versos de Gonçalves de Magalhães que são, inclusive, os mesmos versos utilizados para a construção da epígrafe de um poema posterior de Machado de Assis, também dedicado a Braga. ${ }^{8}$

De acordo com Massa (2009, p. 105), o poema "Saudades", de Machado, foi composto quando Braga tinha retornado a Portugal por um curto período. Nele, o jovem poeta, saudoso e melancólico, expressou sua tristeza diante da ausência do amigo, de quem ele imitava o modo de compor, porque, como assinalou o biógrafo,

Braga não foi apenas um mestre e amigo para Machado de Assis, mas um exemplo imitado, copiado e, digamos a palavra certa, plagiado. A estrela de Braga cegou Machado de Assis, que se mostrou como que fascinado. A admiração lhe fazia naturalmente desejar que as suas poesias se parecessem com as do amigo. (MASSA, 2009, p. 111)

Nesse sentido, "Saudades" se assemelha a muitos poemas das Tentativas poéticas.

Leia-se o poema de Machado de Assis:

\section{Saudades}

Ao Ilm. Snr. F. G. Braga.

Vai oh! meu saudoso canto

Dizer um nome - Saudade!

F. G. Braga.

\footnotetext{
${ }^{8}$ Trata-se do poema "No álbum do Sr. F. G. Braga", publicado na Marmota Fluminense em outubro de 1855 , e que será aqui analisado, posteriormente.
} 
Recebe, ó Braga, o meu canto, Que eu cá de longe t'envio; São orvalhadas do pranto Secas flores do estio; É prova da lealdade

D'uma constante amizade.

Recebe, que o pensamento Tenho em Deus, na pátria, em ti; Das privações no tormento

Do tempo, que te não vi: São flores, dá-lhe cultura, Dá-lhe o porvir da ventura.

No mar do mundo enganoso Há procelas, há bonanças; Procela, é quando saudoso Vive um peito co'as 'speranças; Bonança, é quando amizade Goza paz e f'licidade.

Sofri procela; meus olhos Te não viram com ventura; Soçobrei ante os escolhos Da desgraça e desventura; A dor ceifou da esperança A flor que a saudade alcança.

Cruel ausência! que dias Tão amargos não passei; Que imenso mar d'alegrias Ter contigo não sonhei! Tudo quimera, ilusão, Bem sabia o coração!

Não viçavam minhas flores, Era escuro o firmamento; Não via nele os fulgores, Só via meu sofrimento, Só via pranto, saudade; Era a pura realidade. 
Saudade! bebi na taça

O fel amargo da dor;

Quis horrífica desgraça

Que te não visse, cantor;

Dei de rojo o corpo ao leito,

Sufoquei a dor no peito!

Adeus... não pode minh'alma

Entre suspiros cantar;

Minha dor somente acalma

Se ouvir teu doce trovar,

Que entre o fel, que o peito traga,

Um nome me adoça é - BRAGA. -

Rio de Janeiro, 25 de fevereiro de 1855.

J. M. M. de Assis. (ASSIS, 1855e, p. 4)

A epígrafe foi retirada do poema "Saudades de Pernambuco", de Braga, publicado na Marmota Fluminense no dia 26 de dezembro de 1854, ou seja, antes do início da colaboração de Machado de Assis no periódico do editor Paula Brito. No poema de Braga, o canto melancólico, expresso em sete décimas de versos heptassílabos, foi liberto a fim de que chegasse aos pais e aos irmãos do poeta, porque ele estava saudoso. Além do mais, a paisagem pernambucana serviu de motivo para que o eu-lírico rememorasse momentos íntimos que lá passou. Segue-se a última estrofe de "Saudades de Pernambuco", da qual Machado retirou os versos para a epígrafe de "Saudades":

Longe?... Mui longe!... Qu'importa?

Há de o meu canto saudoso

Transmitir a fé já morta

Do trovador desditoso

Aos entes que quero mais: -

A meus amigos, meus pais!...

De Pernambuco à cidade,

Se é possível fazer tanto,

Vai oh meu saudoso canto

Dizer um nome: - SAUDADE. (BRAGA, 1856, p. 18) 
Tanto no poema de Machado de Assis como no de Gonçalves Braga, o canto é enviado a alguém que se encontra distante do eu-lírico saudoso. O canto do português é íntimo por ser dirigido aos seus amigos e aos seus pais, e Machado também deixa clara a sua relação de forte amizade ao oferecê-lo ao amigo poeta. $\mathrm{O}$ motivo poético não é o único que aproxima os dois poemas, pois "Saudades" foi construído com versos heptassílabos em oito sextilhas que apresentam um sistema de rimas semelhante ao empregado por Braga nos seis primeiros versos das décimas de "Saudades de Pernambuco" (ABABCC). Além disso, em ambos os poemas, o ritmo é marcado por acentuações ora nas segundas, quartas e sétimas; ora nas terceiras, quintas e sétimas.

É interessante observar que, nesse poema consagrado a um português, existem marcas linguísticas que revelam uma maneira de escrever lusitana. Por exemplo, nos versos "Do tempo, que te não vi:" e "Te não viram com ventura", é perceptível a colocação pronominal estranha à fala e escrita dos brasileiros. Como consta na Moderna gramática portuguesa, "diante de negação, o pronome átono pode vir antes ou depois do advérbio não". Porém, como é mostrado com exemplos na gramática, o emprego do pronome átono antes do advérbio é raro entre os brasileiros (BECHARA, 2009, p. 586).

Primeiramente, o eu-lírico de "Saudades" oferece seu canto, figurado como secas folhas do estio que estão orvalhadas com o seu pranto, pedindo ao amigo que as cultive, dando-lhes ventura. Depois, diz o poeta: "que eu cá de longe te envio". O poema foi composto quando Braga estava temporariamente em Portugal, conforme salientou Massa (2009, p. 105), e, assim, depreende-se que o "cá" se refira ao Brasil, local em que se encontrava o poeta fluminense. Nesse sentido, o uso desse é simbólico, porque, novamente, assim como o poema "A palmeira" de Machado de Assis (1855a, p. 3), publicado meses antes na Marmota Fluminense, recupera o imaginário presente no poema "Canção do exílio" (1843) de Gonçalves Dias. ${ }^{9}$ Porém, a referência nacionalista parece atenuada no poema machadiano.

A terceira estrofe traz uma pequena explicação sobre o que é "procela"10 e "bonança". A primeira palavra é definida como aquilo que é

\footnotetext{
${ }^{9}$ O poema "Canção do exílio" foi composto quando Gonçalves Dias estava exilado em Portugal. Assim, usando os versos seguintes como exemplo: "minha terra tem primores, / Que tais não encontro eu cá; / Em cismar - sozinho - à noite - / Mais prazer encontro eu lá; / Minha terra tem palmeiras, / Onde canta o Sabiá" (DIAS, 1846, p. 9); percebe-se que o "cá" e o "lá" foram usados repetidamente, a fim de que o leitor comparasse a pátria do poeta, o Brasil, e o lugar de seu exílio, Portugal. Mais informações sobre o poema podem ser encontradas em Marques (2014).

10 Consta no Grande Dicionário Houaiss on-line a definição de "procela": "1. Forte tempestade no mar com vento intenso e grandes ondas; tormenta, borrasca, temporal" (GRANDE DICIONÁRIO HOUAISS, on-line).
} 
sentido por alguém que está saudoso, sofrendo e com esperanças, e a segunda palavra é definida como o sentimento de amizade que goza paz e felicidade. Assim, o quadro da saudade é construído com os termos: "tormento", "desgraça", "desventura", "dor", "procelas", "cruel", "amargos", "horrífica desgraça" e o verbo "ceifar", porque o eu-lírico passa a relatar o sofrimento pela ausência do amigo. Essas palavras colaboram significativamente para criar a atmosfera de angústia, associadas à dor, pena e sofrimento.

Por outro lado, pode-se dizer que algumas palavras do poema estão relacionadas à construção da figura do elogiado, como "lealdade", "amizade", "f'licidades", "'sperança", "ventura" e "bonanças". No entanto, a impressão é de que elas são poucas, já que a intenção é revelar um sentimento de angústia à moda ultrarromântica, porque o eu-lírico não conseguiu compor durante a ausência do amigo ("Não viçavam minhas flores").

A última estrofe de "Saudades" se assemelha à última do poema "A palmeira" de Machado de Assis, pelo uso de um "Adeus... " de despedida e que, ao mesmo tempo, dramatiza mais a cena. ${ }^{11} \mathrm{O}$ eu-lírico diz que já não pode mais cantar, tendo sua dor aliviada se ouvir o trovar do amigo.

Machado de Assis termina seu poema exatamente como Braga terminara "Saudades de Pernambuco". Neste, lê-se: "Vai oh meu saudoso canto / Dizer um nome: - SAUDADE", e no poema do jovem fluminense: "Que entre o fel, que o peito traga, / Um nome me adoça é - BRAGA. -".

\section{No álbum do Sr. F. G. Braga}

Publicado no dia 9 de outubro de 1855 na Marmota Fluminense, "No álbum do Sr. F. G. Braga" é outro poema escrito em homenagem a Gonçalves Braga. Nele, o poeta fluminense engrandece o amigo português, comparando-o a grandes escritores lusos. O título é um exemplo da moda dos poetas românticos em escrever poemas no "álbum", espécie de caderninho de poemas, dos companheiros das letras. A Marmota Fluminense, por exemplo, está recheada de textos poéticos intitulados "N'um álbum", "No álbum de um jovem", "No álbum de uma senhora" etc.

Eis o poema de Machado de Assis:

${ }^{11}$ Trata-se de "Adeus, palmeira! ao cantor / Guarda o segredo de amor; / Sim, cala os segredos meus! / Não reveles o meu canto, / Esconde em ti o meu pranto / Adeus, ó palmeira!... adeus! " (ASSIS, 1855a, p. 3). 
No álbum do Sr. F. G. Braga

Pago ao gênio um tributo merecido

Que a gratidão me inspira;

Fraco tributo, mas nascido d'alma.

MAG. Saudades.

Qual descantou na lira sonorosa

O terno Bernardim com voz suave;

Qual em tom jovial cantou Elmano

Brandas queixas de amor, tristes saudades

Que em seus cantares mitigou; oh! Vate,

Assim da lira tu, ferindo as cordas,

Cantas amores que em teu peito nutres,

Choras saudades que tu'alma sente;

Ou ergues duradouro monumento

À cara pátria que distante choras.

Do Garrett divino - o Vate excelso

Renasce o brilho inspirador das trovas,

Das mimosas canções que o mundo espantam

Nesse canto imortal sagrado aos manes

Do famoso Camões, cantor da Lísia (1)

São carmes que te inspira o amor da Pátria.

Nele relatas em divinos versos

O exímio Trovador, a inteira vida

Já no campo de Marte; já no cume

Do Parnaso bradando aos povos todos

Os feitos imortais da lusa gente!

Nessa epopeia, monumento excelso

Que em memória do Vate à pátria ergueste, Ardente se desliza a etérea chama,

Que de Homero imortal os sucessores

Na mente ateia o céu com forte sopro!

Euterpe, a branda Euterpe nos teus lábios

Da taça d'ouro, derramando o néctar

Deu-te a doce [poesia] com que outr'ora

Extasiou Virgílio ao mundo inteiro!

"Empunha a lira d'ouro, e canta altivo

"Um Tasso em ti se veja - o estro excelso

"De Camões imortal, te assoma à mente; 
"E de verde laurel cingida a fronte

"Faz teu nome soar na voz da fama!"

Foram estas as frases com que Apolo

Poeta te fadou quando nasceste,

E em doce gesto te imprimiu na fronte

Um astro de fulgor, que sempre brilha!

Ah! que não possam estes pobres versos, Que n'áureas folhas de teu belo livro Trêmulo de prazer co'a destra lanço, Provar-te o assombro, que ao ouvir-te sinto!

Embora!... entre os arquejos de minh'alma

Do opresso coração entre os suspiros As brandas vibrações da pobre lira Vão em tua alma repetir sinceros Votos dest'alma que te prove o assombro Que sinto ao escutar-te as notas d'harpa!

Rio de Janeiro 1855.

$$
\text { J.M.M.d'Assis. }
$$

(1) um belo poema do Snr. Braga, intitulado - Camões. (ASSIS, 1855d, p. 3-4)

Os versos da epígrafe pertencem ao poema "O gênio e a música" de Gonçalves de Magalhães. Esse poema, formado por estrofes de número variado de versos decassílabos e hexassílabos, foi dedicado à cantora lírica Angelica Catalani, ${ }^{12}$ que é exaltada em todo o texto poético como o gênio que foi inspirado pela natureza para a produção de belas músicas. Os versos "pago ao gênio um tributo merecido / Que a gratidão me inspira; / Fraco tributo, mas nascido d'alma" finalizam o poema que tem como propósito homenagear a cantora com o canto que vem diretamente da alma do poeta. Esses versos estão bem encaixados no início do poema de Machado de Assis, porque ele também considera seu amigo português como um gênio digno de receber tributo.

Como dito anteriormente na análise do poema "Saudades", Braga se apropriou dos mesmos versos de "O gênio e a música" para a composição da

12 De nacionalidade italiana, estreou em Lisboa em 1801 como protagonista da ópera La morte di Semiramide, com o libreto de Giuseppe Caravita (NUNES, 2012, p. 12). 
epígrafe do seu poema "Saudação poética ao Senhor Conselheiro António Feliciano de Castilho". Esse poema de Braga saiu na Marmota Fluminense em maio de 1855, isto é, cinco meses antes da publicação do poema "No álbum do Sr. F. G. Braga" de Machado de Assis, e na mesma edição em que o brasileiro publicou o poema "Saudades". Em "Saudação poética ao Senhor Conselheiro António Feliciano de Castilho", formado por estrofes de número variado de versos e cuja primeira e segunda partes contêm versos decassílabos e a terceira e última parte, heptassílabos, a epígrafe possui a mesma finalidade que no poema machadiano, ou seja, anunciar que o poeta, inspirado por um sentimento de gratidão, vai exaltar certa pessoa, no caso, Castilho.

O poema "No álbum do Sr. F. G. Braga" é formado por quatro estofes: a primeira e a última são décimas e a segunda e terceira, irregulares com dezesseis e trezes versos, respectivamente. O metro é o decassílabo (heroico e sáfico) com acentuações variadas e não há rimas. ${ }^{13}$ Ademais, ele se destaca entre os demais poemas publicados anteriormente por Machado na imprensa, porque o poeta usou mais o enjambement, como nos versos "Deute a doce [poesia] com que outr'ora ${ }^{14}$ / Extasiou Virgílio ao mundo inteiro! "; apresentou uma maior variedade de léxico; e construiu mais sentenças invertidas sintaticamente, as quais permitem um rebuscamento da expressão.

$\mathrm{Na}$ primeira estrofe, Machado primeiro igualou Braga ao poeta descrito como possuidor da "lira sonorosa", Bernardim Ribeiro, o qual tinha sido citado no poema "A saudade" de Braga, que serviu alguns versos à epígrafe de "A saudade" de Machado de Assis, ${ }^{15}$ e ao poeta que cantou "queixas de amor, tristes saudades", Elmano Sadino, pseudônimo de Manuel Maria Barbosa du Bocage. Na segunda metade da primeira estrofe, Braga foi descrito como um "vate" que canta amores, chora saudades e dedica versos à pátria distante. Desse modo, o jovem fluminense resumiu, em cinco versos, os temas poéticos prediletos do poeta amigo.

$\mathrm{Na}$ segunda estrofe, o eu-lírico destacou a beleza dos versos do poema "Camões", de autoria de Braga, afirmando que o "cantor da Lísia" e "exímio Trovador" inspirou profundamente o jovem poeta português. Esse

13 O poema "A saudade" de Machado de Assis, publicado quatro dias antes na Marmota Fluminense, também possui estrofe irregular e decassílabos brancos, assim como o poema de Braga, "Saudação poética ao Senhor Conselheiro António Feliciano de Castilho".

${ }^{14} \mathrm{Na}$ edição da Marmota Fluminense, esse verso aparece assim: "deu-te a doce com que outr'ora", entretanto, se assim fosse, ele não alcançaria as dez sílabas poéticas, nem faria sentido. Em $A$ poesia completa, o verso aparece com a palavra "poesia" em seu interior, sem a menção de que foi acrescentado por terceiros (ASSIS, 2009, p. 401-402).

15 "Saudade! Ó casta virgem, / Qu'inspiraste a Bernardim, / Nos meus dias de tristeza / Consolar tu vens a mim." (BRAGA, 1856, p. 59). 
poema, dedicado a Castilho, está presente nas Tentativas poéticas. Contém epígrafe com os versos de Garrett: "ao nome lusitano, / O nome de Camões eterno se une", e tem aqui as duas primeiras estrofes reproduzidas:

Do sepulcro rasgai negro manto,

Gênios grandes das grandes nações,

Vinde todos ouvir o meu canto

Precedido do nome - CAMÕES.

D'esse nome que os vates inspira,

D'esse nome que os povos espanta,

Cujo vate com os cantos da lira

Sobre todos, qual rei se alevanta.

[...] (BRAGA, 1856, p. 48)

Nesse poema, formado por quadra de versos eneassílabos, predomina o tom narrativo já que o eu-lírico conta os principais fatos da vida de Camões.

Assim como o poema "A saudade" de Machado de Assis, provavelmente composto numa data próxima à feitura deste, "No álbum do Sr. F. G. Braga" apresenta termos que se referem à mitologia greco-romana. O trecho "Já no campo de Marte; ${ }^{16}$ já no cume / Do Parnaso ${ }^{17}$ bradando aos povos todos / Os feitos imortais da lusa gente!" faz referência a Camões, que cantou as conquistas portuguesas em Os lusíadas. A menção à cultura grecoromana é devida à crença do poeta fluminense de que esta obra poética do quinhentista pode ser igualada às obras do poetas antepassados. Além disso, a imagem de Camões no monte Parnaso pode ser associada à do profeta, que no cume da montanha recebe as mensagens divinas e, assim, percebe-se aqui uma relação com o ensaio de crítica literária, "A poesia", pertencente à série "Ideias Vagas", ${ }^{18}$ em que Machado afirmou "O que vos inspira aquele quadro sublime - quando no cume de uma montanha devassais com olhar e com espírito - o vale dourado pelos últimos reflexos do sol [...]" (ASSIS, 2013, p. 54), referindo-se ao poeta.

16 "Marte é o deus romano identificado ao Ares helénico [...]. Na época clássica, Marte surge em Roma como o deus da Guerra. Mas essa não é a sua única atribuição" (GRIMAL, 2005, p. 291-292).

17 Montanha nomeada Parnaso e localizada na Grécia, consagrada ao deus Apolo (GRIMAL, 2005, p. 356).

18 "Ideias Vagas" é o nome de uma pequena série de textos de Machado de Assis, publicados durante o ano de 1856 e assim intitulados: "A poesia", "A comédia moderna" e "Os contemporâneos" (Parte I Monte Alverne e Parte II). 
O eu-lírico machadiano insere o nome de Garrett, assim como o de Camões. E como Braga possui um poema intitulado "Almeida Garrett", composto no dia da morte deste e que, portanto, faz uma homenagem lúgubre ao poeta, é possível que Machado tenha se referido ao dito poema, elogiando-o com os versos: "Do Garrett divino - o Vate excelso / Renasce o brilho inspirador das trovas, / Das mimosas canções que o mundo espantam / Nesse canto imortal sagrado aos manes". ${ }^{19}$ Dessa maneira, o canto imortal sagrado aos antepassados seria de Braga. Leia-se a primeira estrofe do poema "Almeida Garrett":

Já não vive o cantor do luso bardo, Que a pátria celebrou!

Garrett já não vive! A Lísia chora

Quem seu Camões cantou. (BRAGA, 1856, p. 153)

$\mathrm{Na}$ terceira estrofe, o eu-lírico diz que do mesmo modo como Virgílio foi extasiado pela poesia, Braga a recebeu de Euterpe ${ }^{20}$ pois esta, "Da taça d'ouro, derramando o néctar / Deu-te a doce [poesia] com que outr'ora / Extasiou Virgílio ao mundo inteiro!". Não contente em engrandecer o amigo, o poeta afirmou que o deus Apolo ${ }^{21}$ destinou Braga a um caminho magnífico, comparando-o a Torquato Tasso. ${ }^{22}$ Assim, Machado de Assis exageradamente descreveu e elogiou seu mestre e amigo português a partir dos poetas preferidos deste, pois o próprio Braga escreveu no prólogo do seu livro de versos que não buscava glórias, as quais estão somente nos "Tassos e Camões" (BRAGA, 1856, p. 3).

$\mathrm{Na}$ última estrofe, o eu-lírico suspira e espera ansiosamente que seu canto no "belo livro" do amigo seja recebido de bom grado. E, por isso, ele diz humildemente: "Ah! que não possam estes pobres versos, / Que n'áureas folhas de teu belo livro / Trêmulo de prazer co'a destra lanço, / Provar-te o assombro, que ao ouvir-te sinto!". São "sinceros votos" de um amigo que o compara a grandes poetas da literatura greco-latina e portuguesa. Braga

\footnotetext{
19 "Os Manes são, nas crenças romanas, as almas dos mortos" (GRIMAL, 2005, p. 289).

20 Euterpe é uma das noves filhas de Mnemósine e Zeus, as quais receberam a denominação de Musas, que eram cantoras divinas. A cada uma foi atribuída uma função e Euterpe recebeu a flauta (GRIMAL, 2005, p. 319-320).

21 "Apolo é um deus [grego] que pertence à segunda geração dos Olímpicos, filho de Zeus e de Latona e irmão da deusa Ártemis. [...] Era como deus da música e da poesia que Apolo era representado sobre o monte Parnaso, onde presidia os jogos das Musas. Os seus oráculos eram geralmente expressos em fórmulas versificadoras, e passava por inspirar tanto os adivinhos como os poetas" (GRIMAL, 2005, p. 32).

22 Braga possui um poema curto intitulado "Torquato Tasso" e datado de abril de 1856, o que indica que o autor era apreciador da poesia do italiano (BRAGA, 1856, p. 169).
} 
publicou resposta na mesma revista, cinco dias após a publicação do poema de Machado de Assis, na forma de um poema composto de duas estrofes com versos decassílabos e hexassílabos:

Ao Senhor J. M. M. D’Assis.

(EM RESPOSTA).

Com que expressões eu hei de agradecer-te

Meu bom, e caro amigo,

Os versos sonorosos com que horaste

A minha estéril musa?

Na mente confundida em vão procuro

Uma ideia somente

Que te diga a emoção que sinto n'alma

Ao ler os versos teus,

Construídos de frases lisonjeiras

Que confundem meu estro!

Mas qu'importa que a mente esteja rude

Se tem fogo meu peito,

Se sente, e os lábios meus dizer-te podem

Seus puros sentimentos,

Em dois termos somente reunidos:

Gratidão, Amizade?

Rio, 10 de outubro de 1855.

F. Gonçalves Braga. (BRAGA, 1855, p. 4)

Escrito um dia após a publicação do texto poético de Machado de Assis, o poema dá a impressão de composição rápida, sugerindo que o poeta não dedicou muito tempo para oferecer versos sublimes e de exaltação ao brasileiro. O eu-lírico diz que "a mente [está] rude" e somente agradece os versos lisonjeiros, sem comparar Machado aos bons poetas, elogiar qualquer um de seus poemas ou usar os deuses mitológicos para dizer que o amigo possui a poesia como um dom. Assim, conforme Massa, "depois dessa resposta de Braga, o jovem poeta cessou de queimar incenso diante daquele altar. Braga já não era mais o seu mestre; era um igual, um irmão [...] o discípulo, há muito, já se emparelhara e em seguida ultrapassou o modelo" (MASSA, 2009, p. 106). 
Por fim, vale destacar uma última vez em que Braga colaborou para o aprendizado inicial de Machado de Assis.

O poema machadiano "Saudades" se assemelha formalmente ao poema de que se serviu sua epígrafe, "Saudades de Pernambuco", do jovem mestre português. A língua deste aparece na sintaxe do poema do brasileiro. Além disso, o motivo poético é o mesmo, porque o eu-lírico de "Saudades" é melancólico e dirige seu canto saudoso ao amigo ausente, que anteriormente havia expressado o mesmo sentimento pelos amigos e pelos pais distantes, com imagens semelhantes.

Como demonstrado, o poema "No álbum do Sr. F. G. Braga" confirma que o jovem poeta brasileiro considerava Braga como referência importante, já que este foi comparado aos grandes poetas lusos Bernardim Ribeiro e Bocage, ao italiano Torquato Tasso e ao latino Virgílio. Ademais, os poemas do português "Camões" e "Almeida Garrett" foram altamente valorizados. Assim, se o apreço pelo jovem mestre era grande e notável, provavelmente, Machado lia e estudava os escritores preferidos do português, copiando seus temas e compartilhando seus sentimentos.

\section{Referências}

ASSIS, Machado de. A palmeira. Marmota Fluminense, Rio de Janeiro, n. 540, jan. $1855 \mathrm{a}$.

_. A saudade. Marmota Fluminense, Rio de Janeiro, n. 632, out. $1855 \mathrm{~b}$. . Ela. Marmota Fluminense, Rio de Janeiro, n. 539, jan. 1855c.

. No álbum do Sr. F. G. Braga. Marmota Fluminense, Rio de Janeiro, n. 634, out. 1855 d.

Saudades. Marmota Fluminense, Rio de Janeiro, n. 578, mai. 1855e.

. A Madame Arsène Charton Demeur. Diário do Rio de Janeiro, n. 38, fev. 1856. . Poesias completas. Rio de Janeiro: B. L. Garnier, 1901.

. Machado de Assis: a poesia completa. Organização e fixação dos textos por Rutzkaya Queiroz dos Reis. São Paulo: EdUSP; Nankin, 2009.

Machado de Assis: crítica literária e textos diversos. Organização de Sílvia

Maria Azevedo, Adriana Dusilek e Daniela Mantarro Callipo. São Paulo: Editora Unesp, 2013.

BECHARA, Evanildo. Moderna gramática portuguesa. 37. ed. Rio de Janeiro: Nova Fronteira, 2009.

BRAGA, Francisco Gonçalves. Requerimento a Diogo Soares da Silva de Bivar, solicitando exame censório para a peça: Maria Espanhola. Coleção Conservatório Dramático Brasileiro, ${ }^{\circ}$ 131. Rio de Janeiro, 04/08/1854. 3 doc. (7 p.). Disponível 
em: <http://objdigital.bn.br/objdigital2/acervo_digital/div_manuscritos/mss1453 556/mss1453556.pdf >. Acesso em: 5 jul. 2018.

. Ao senhor J. M. M. d'Assis. Marmota Fluminense, Rio de Janeiro, n. 636, out. 1855.

Tentativas poéticas. Rio de Janeiro: Tipografia de Nicolau Lobo Vianna \& Filhos, 1856.

CARVALHO LIMA et al. Álbum do Grêmio Literário Português no Rio de Janeiro. Rio de Janeiro: Tipografia de Teixeira e C., 1858.

CORREIO MERCANTIL, E INSTRUTIVO, POLÍtICO, UNIVERSAL. Rio de Janeiro, n. 76, 17 mar. 1860a.

CORREIO MERCANTIL, E INSTRUTIVO, POLÍtiCO, UNIVERSAL. Rio de Janeiro, n. 79, 20 mar. 1860b.

DIÁRIO DE PERNAMBUCO. Recife, n. 240, 23 out. 1847.

DIÁRIO DO RIO DE JANEIRO. Rio de Janeiro, n. 80, 24 mar. 1858.

DIAS, Gonçalves. Primeiros cantos. Rio de Janeiro: Tipografia Universal de Laemmert, 1846.

GRANDE DICIONÁRIO HOUAISS. Disponível em: <https://houaiss.uol.com.br >. Acesso em: 10 fev. 2018.

GRIMAL, Pierre. Dicionário da mitologia grega e romana. Tradução de Victor Jabouille. 5. ed. Rio de Janeiro: Bertrand Brasil, 2005.

MAGALHÃES JÚNIOR, Raimundo. Machado de Assis: vida e obra (aprendizado). 2. ed. Rio de Janeiro; São Paulo: Record, 2008. v. 1.

MARQUES, Wilton José. As primeiras incertezas, o profeta machadiano e o malogro do primeiro livro. Machado de Assis em Linha: revista eletrônica de estudos machadianos, Rio de Janeiro, v. 9, n. 19, p. 11-33, dez. 2016. Disponível em: <http://www.scielo.br/pdf/mael/v9n19/1983-6821-mael-9-19-0011.pdf>. Acesso em: 15 jan. 2018.

O poeta do lá. São Carlos: EdUFSCar, 2014.

MASSA, Jean-Michel. A juventude de Machado de Assis: ensaio de biografia intelectual (1839-1870). 2. ed. São Paulo: Editora Unesp, 2009.

NUNES, Maria Catarina Dias. La morte di Semiramide de Marcos Portugal: estudo, transcrição e edição crítica. 2012. 592 f. Dissertação (Mestrado em Ciências Musicais - Musicologia Histórica) - Faculdade de Ciências Sociais e Humanas, Universidade Nova de Lisboa, Lisboa, 2012.

O LIBERAL PERNAMBUCANO. Recife, n. 464, 28 abr. 1854.

SOUSA, José Galante de. Machado de Assis e outros estudos. Rio de Janeiro: Cátedra; Brasília: INL, 1979.

CRISTIANE NASCIMENTO RODRIGUES é doutoranda pelo Programa de Pós-Graduação em Estudos de Literatura da UFSCar (PPGlit). É mestra pelo Programa de Pós-Graduação em Estudos Literários da Unesp Araraquara. Possui graduação em Licenciatura Plena em Português/Espanhol pela UFSCar. Recentemente publicou o artigo "Machado de Assis: o 
poeta jovem, a palmeira e a lua" (2017) na ATHENA - Revista científica dos discentes do PPGEL - Unemat e o trabalho completo "Machado de Assis e o primeiro ensaio de crítica literária" (2016) nos anais do XVII Seminário de Pesquisa do PPGEL e III Seminário Internacional de Estudos Literários - Unesp Araraquara. Participa do grupo Núcleo de Estudos Oitocentistas - NEO/UFSCar. E-mail: cristiane.rodrigues22@hotmail.com

Recebido: 01.05.2018 Aprovado: 20.06.2018 